Document downloaded from:

http://hdl.handle.net/10251/65197

This paper must be cited as:

Gonzalez, S.; Arce Vila, P.; Guerri Cebollada, JC. (2015). Buffering Technique for Optimizing Energy Consumption in the Transmission of MultimediaTraffic in Ad-Hoc Networks. IEEE Latin America Transactions. 13(1):250-258.

doi:10.1109/TLA.2015.7040655.

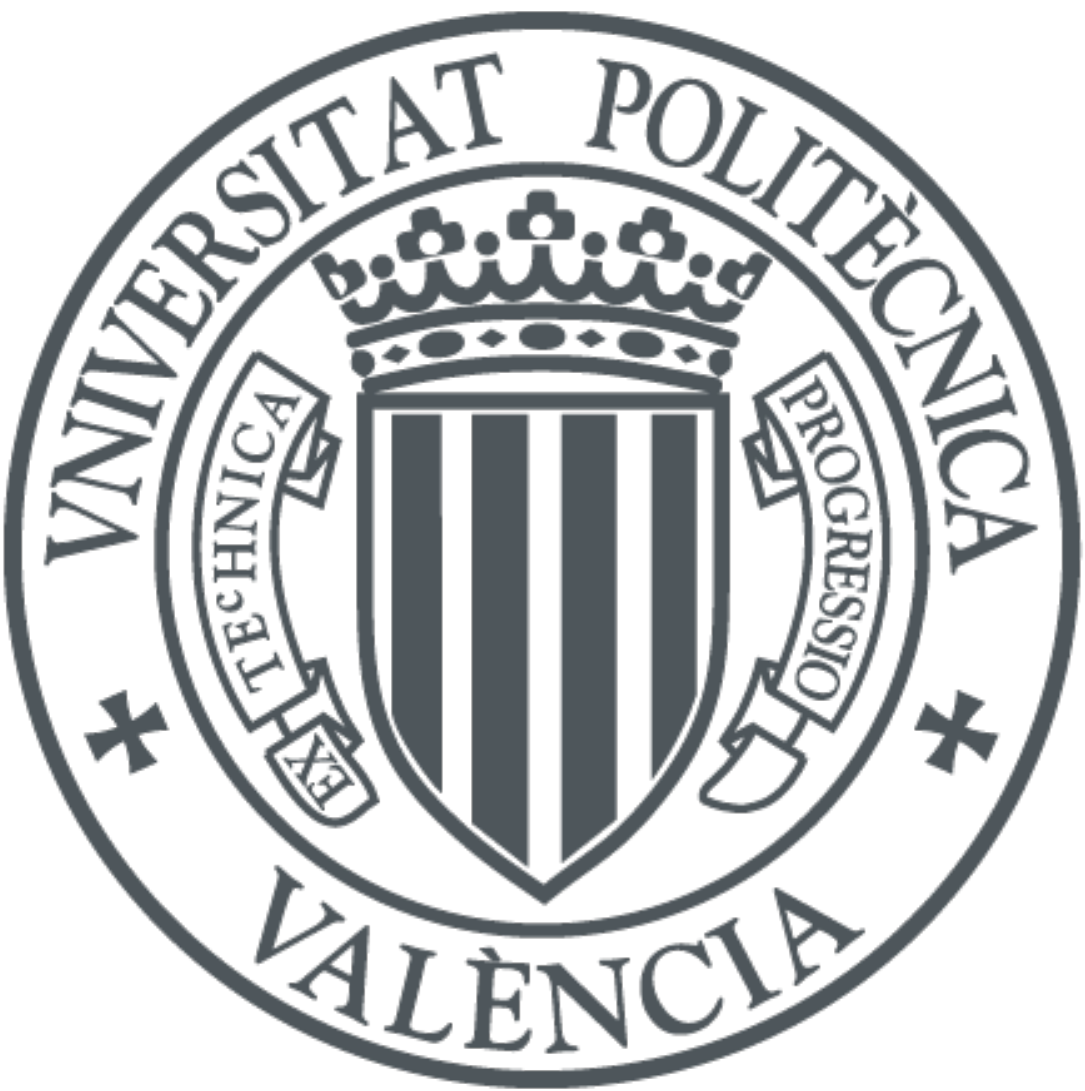

The final publication is available at

http://dx.doi.org/10.1109/TLA.2015.7040655

Copyright Institute of Electrical and Electronics Engineers (IEEE)

Additional Information 


\title{
Buffering Technique for Optimizing Energy Consumption in the Transmission of Multimedia Traffic in Ad-Hoc Networks
}

\author{
S. González, Member, IEEE, P. Arce and J.C. Guerri
}

\begin{abstract}
Energy constraints on wireless nodes represent a current field of research. Such restrictions are particularly significant because of the great amount of features and applications currently available on devices, which contribute to dramatically increase energy consumption. However, when transmitting delay-sensitive data, such as multimedia streaming, a balance between energy optimization and quality of service is required. In this sense, there are many works that address this issue from different layers of network architecture separately; however, a more efficient solution could be achieved by combining the management capabilities of the different layers and the joint use of such information, which is called a crosslayer mechanism. Moreover, despite the fact that the IEEE 802.11 standard defines an energy management mechanism at MAC level, it is envisaged only for structured networks, leaving just general guidelines for other kind of networks, such as AdHoc networks. Therefore, as a first step towards the design of a cross-layer scheme, this paper analyzes the flaws of IEEE 802.11 standard as regards the infrastructureless mode and proposes an optimization mechanism for energy management in Ad-Hoc networks. The proposed approach is based on a buffering mechanism, which is able to increase power-saving periods of time in Ad-Hoc nodes. Simulations using NS3 indicate that it possible to obtain higher levels of residual energy at the end of a transmission using the proposed scheme.
\end{abstract}

Keywords-Energy Aware QoS, Energy Efficiency, Multimedia, Ad-Hoc Networks.

\section{INTRODUCCIÓN}

$\mathrm{E}$ L significativo crecimiento en el uso de dispositivos móviles ha generado un gran interés en la investigación de nuevos escenarios de comunicación, por ejemplo el despliegue de redes oportunistas basadas en dispositivos de usuario como smartphones [1]. En ese sentido un modo de comunicación Ad-Hoc representa una potencial solución para este tipo de escenarios. Sin embargo uno de los principales desafíos que enfrenta el despliegue de redes Ad-Hoc, es la limitada capacidad de energía de los dispositivos debido al uso de baterías.

S.González, Universitat Politècnica de València, Instituto de Telecomunicaciones y Aplicaciones Multimedia (iTEAM), España, sangonma@posgrado.upv.es.

P.Arce, Universitat Politècnica de València, Instituto de Telecomunicaciones y Aplicaciones Multimedia (iTEAM), España, paarvi@iteam.upv.es.

J.C.Guerri, Universitat Politècnica de València, Instituto de Telecomunicaciones y Aplicaciones Multimedia (iTEAM), España, jcguerri@dcom.upv.es.
En particular el consumo de energía se incrementa con la cantidad de datos que se transmiten.

En ese sentido las mejoras alcanzadas en cuanto a tasas de transmisión en los estándares 802.11n/ac, así como la diversidad de aplicaciones disponibles en dispositivos como fuentes de datos en especial multimedia, incrementa dramáticamente el flujo de tráfico y por tanto el consumo de energía.

La limitada capacidad de energía degrada la conectividad y por tanto el tiempo de operación de una Red Ad-Hoc, de ahí la necesidad de implementar esquemas de gestión de energía. Sin embargo dicha gestión no debe ser realizada en detrimento de la calidad de la transmisión del flujo de datos. En particular el presente artículo se enfoca en la problemática del balance entre la calidad de servicio requerida por un tráfico de datos sensible al retardo y las restricciones de energía de los dispositivos terminales.

En ese sentido el estándar IEEE 802.11 [2], define un mecanismo de gestión de energía básico denominado PSM (Power Save Mode) y adicionalmente un esquema mejorado denominado APSD (Automatic Power Save Delivery), el cual implementa un mecanismo de calidad de servicio basado en diferenciación de tráfico. Los mecanismos emplean un sistema de señalización a nivel MAC coordinado por la estación central o punto de acceso, con el objetivo de asignar intervalos de bajo consumo de energía a las estaciones asociadas. Los esquemas de gestión de energía mencionados, sin embargo han sido especificados en el estándar para un modo de funcionamiento estructurado ó BSS (Basic Service Set), describiendo únicamente conceptos generales para un entorno Ad-Hoc ó IBSS (Independent BSS).

En el presente trabajo se ha diseñado una propuesta con el objetivo de optimizar el consumo de energía durante la transmisión de tráfico multimedia en una red en modo AdHoc.

El esquema planteado emplea un sistema de almacenamiento o buffering de los datos a transmitir, con el objetivo de incrementar los periodos de ahorro de energía de las estaciones. El mecanismo trabaja en la capa de aplicación, en conjunto con un sistema de señalización propuesto para la capa MAC.

La propuesta ha sido implementada sobre el simulador NS3 y verificada con mediciones realizadas sobre equipos reales.

Los resultados obtenidos muestran una reducción del gasto de energía en los dispositivos. 
El artículo está organizado de la siguiente forma: en la Sección II, se presenta el estado del arte de trabajos relacionados, enfocados en estrategias planteadas para alcanzar un balance entre eficiencia de energía y QoS en redes Ad-Hoc. En la Sección III, se analiza el esquema de gestión de energía definido en el estándar IEEE 802.11. En la Sección $\mathrm{IV}$, se describe la propuesta para optimizar el consumo de energía en un entorno Ad-Hoc. La evaluación del esquema planteado se presenta en la Sección V. Finalmente en las Secciones VI y VII, se presentan respectivamente las conclusiones y líneas futuras de trabajo.

\section{ESTADO DEL ARTE}

A continuación de describen un conjunto de trabajos relacionados. Las propuestas han sido clasificadas siguiendo una arquitectura de red.

Un primer conjunto de soluciones gestionan el balance entre el consumo de energía y calidad de servicio a nivel de capa física y MAC. Estas propuestas se enfocan en optimizar el acceso al medio, tratando de minimizar periodos de latencia debido a la contención. Específicamente en [3] se plantea un protocolo MAC denominado Q-MAC, que establece diferenciación de servicios. La propuesta apunta a reducir la latencia debido a los tiempos de espera para el acceso al canal y con ello disminuir el consumo de energía.

Un análisis similar se plantea en [4], mediante un sistema de ajuste adaptativo de la ventana de contención. Ambas propuestas plantean esquemas conceptualmente muy similares al estándar IEEE 802.11e.

El estándar IEEE 802.11, define un esquema de gestión de energía asociado a un mecanismo de señalización para informar a las estaciones destino acerca de la existencia de tráfico. En [5] y [6] se describen trabajos que proponen incluir información adicional acerca de las características del tráfico y niveles de energía en la señalización mencionada.

Una estrategia consistente en la conformación de redes estructuradas temporales se describe en [7]. El trabajo propone incluir en una red Ad-Hoc, un conjunto de nodos fijos, los cuales operan a intervalos con el objetivo de aliviar la congestión, disminuyendo el consumo de energía en nodos intermedios. Un mecanismo similar se describe en [8], mediante un esquema de clustering que permite la asignación de funciones de punto de acceso a ciertos nodos de una red Ad-Hoc. Dicha asignación es distribuida a lo largo del tiempo para equilibrar el nivel de energía en la red.

A nivel de capa de red, también se presentan un conjunto de propuestas. El general los trabajos proponen incluir información acerca del nivel de energía residual en los nodos, para la definición del coste de ruta y toma de decisiones para el envío. Los nodos con la mayor energía residual conforman trayectorias que son catalogadas como las más óptimas. El esquema puede ser combinado en conjunto con estrategias adicionales, por ejemplo: enrutamiento multi-trayectoria, diferenciación de servicios, predicción de distorsión en el caso de tráfico de video y monitorización de rutas para evitar sobrecarga. En [9], [10] y [11] se presentan algunos trabajos de éste tipo. La gestión de energía a nivel de red también puede ser direccionada a través de métricas indirectas, como por ejemplo el retardo. En particular la conformación de rutas con el menor coste de retardo, permitiría un mayor número de transmisiones exitosas disminuyendo por tanto el consumo de energía debido a la reducción de reintentos de transmisión. En [12], [13], [14], se presentan trabajos que siguen ésta esquema.

Sin embargo considerando que la capa MAC maneja información acerca del acceso al medio, una gestión de éste tipo resultaría más eficiente a ese nivel de arquitectura de red.

A nivel de aplicación, también es posible definir propuestas para optimizar el consumo de energía mientras se garantizan los requerimientos del tráfico. En [15], se describe una trabajo que aprovecha las capas de mejora de los sistemas de codificación H.264/SVC para adaptar dinámicamente la calidad de video, acorde a las características instantáneas de los nodos. Por ejemplo, una reducción de la calidad de video permite disminuir el volumen de tráfico, reduciendo el consumo de energía. Sin embargo un planteamiento de éste tipo requiere considerar adicionalmente un balance entre la codificación adaptativa y la calidad percibida.

El balance entre calidad de servicio y eficiencia energética, puede ser analizado con un enfoque diferente a los descritos, mediante el trabajo en conjunto de varias capas dentro de la arquitectura de red. A éste tipo de esquema se denomina cross-layer. Un enfoque de éste tipo tiene la ventaja de aprovechar la información disponible a través de toda la pila de protocolos y por tanto mayor capacidad de gestión.

El desafío de un esquema de este tipo consiste en determinar las capas de la arquitectura de red que pueden contribuir a solucionar un problema y sobre todo definir los mensajes e información que se puede intercambiar entre ellas con tal objetivo.

Un diseño cross-layer, enfocado a la provisión de calidad de servicio en redes Ad-Hoc, se describe en [16], mediante el trabajo en conjunto de la capa de Red y MAC. Por otra parte una interacción a nivel de Aplicación - MAC se plantea en [17]. El trabajo describe un mecanismo de asignación de prioridades en los datos a nivel de las capas superiores para un posterior mapeo hacia las diferentes categorías de acceso a nivel MAC, definidas en el estándar IEEE 802.11e.

En relación a la gestión de energía en [18] se describe un diseño cross-layer que permite una interacción a nivel de la capa física y MAC, específicamente se plantea un esquema de acceso al medio en función de las condiciones del canal.

Finalmente en [19], se describe una propuesta que plantea la interacción de las capas física, MAC y Red, con el objetivo de alcanzar un esquema de routing acorde a las restricciones de energía. Las propuestas descritas sin embargo no abordan la gestión de QoS-Energía en conjunto.

\section{GESTIÓN DE ENERGÍA: ESTÁNDAR IEEE.802.11}

El estándar IEEE 802.11, define un esquema básico de gestión de energía (PSM), basado en un mecanismo de señalización para notificación de tráfico.

El esquema presenta algunas variantes en función del modo de operación: estructurado ó Ad-Hoc. Adicionalmente un 
esquema mejorado denominado APSD, es soportado en modo $B S S$. En los siguientes apartados se describen los mecanismos.

\section{A. Power Save Mode en una Red modo BSS}

La interfaz radio de una estación puede conmutar entre cuatro estados: transmisión (Tx), recepción (Rx), idle (escucha el canal) y sleep (desactivado), un ejemplo del consumo de energía de éstos niveles se puede apreciar en la Fig. 1.

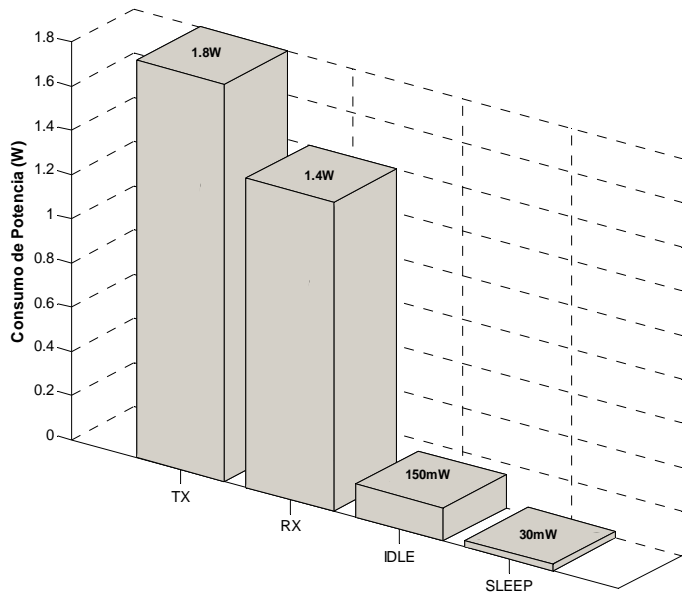

Figura 1. Consumo de Energía de la Interfaz Radio para la Tarjeta Intel PRO/Wíreless 3945ABG.

El objetivo de un sistema de gestión de energía, consiste en permitir que una estación conmute a un estado de menor consumo (sleep), durante el mayor tiempo posible sin sacrificar la conectividad. En modo BSS, por definición un $A P$ (Access Point), conoce la localización de las estaciones móviles y a su vez las estaciones pueden comunicarle su estado de energía. Además el $A P$ debe permanecer en un estado activo todo el tiempo, ya que se asume tiene acceso continuo a una fuente de energía eléctrica. Considerando esas características, es claro que el $A P$ tiene un rol clave en la gestión de energía en una red estructurada. Específicamente tiene dos tareas relacionadas a la gestión de energía. En primer lugar considerando que conoce el modo de operación de cada estación asociada, puede determinar si un frame debe ser enviado, debido a que la estación se encuentra activa ó debe ser almacenado si la estación está en modo sleep. Ahora bien, el almacenamiento ó buffering de los frames por sí solo no habilita a las estaciones a recoger sus datos.

En consecuencia, la segunda tarea de un $A P$ es anunciar periódicamente a las estaciones que tienen frames almacenados. Esto se realiza mediante una notificación en el campo TIM (Traffic Information Message) de un frame Beacon. Previamente durante el proceso de asociación, las estaciones acuerdan con el $A P$ los intervalos Beacon que permanecerán en modo de ahorro de energía. En la Fig. 2 se presenta el esquema de gestión descrito.

\section{B. Esquema de Calidad de Servicio: IEEE 802.11e}

La capa MAC básica emplea la Función de Coordinación Distribuida $(D C F)$ para compartir el medio entre múltiples estaciones. Esto tiene algunas limitaciones: si una cantidad significativa de estaciones intentan comunicarse al mismo tiempo es posible que se produzca un gran número de colisiones, además dicha función no proporciona garantías de QoS.

IEEE 802.11e mejora el mecanismo DCF, mediante una nueva función de coordinación denominada HCF (Función de Coordinación Híbrida). Dentro de HCF existe dos métodos de acceso al canal: HCCA (Controlled Channel Access) y EDCA (Enhanced Distributed Channel Access). Ambos EDCA y HCCA definen categorías de tráfico.

Con EDCA, el tráfico de alta prioridad tiene una mayor oportunidad de ser enviado que el tráfico de baja prioridad, esto se logra mediante el protocolo TCMA (Tiered Contention Multiple Access), el cual es una variación de CSMA/CA, que emplea un espacio arbitrario inter-frame más corto para paquetes de alta prioridad. Por otra parte en HCCA, el AP puede iniciar periodos de libre contención para las estaciones, intercalados con intervalos de contención.

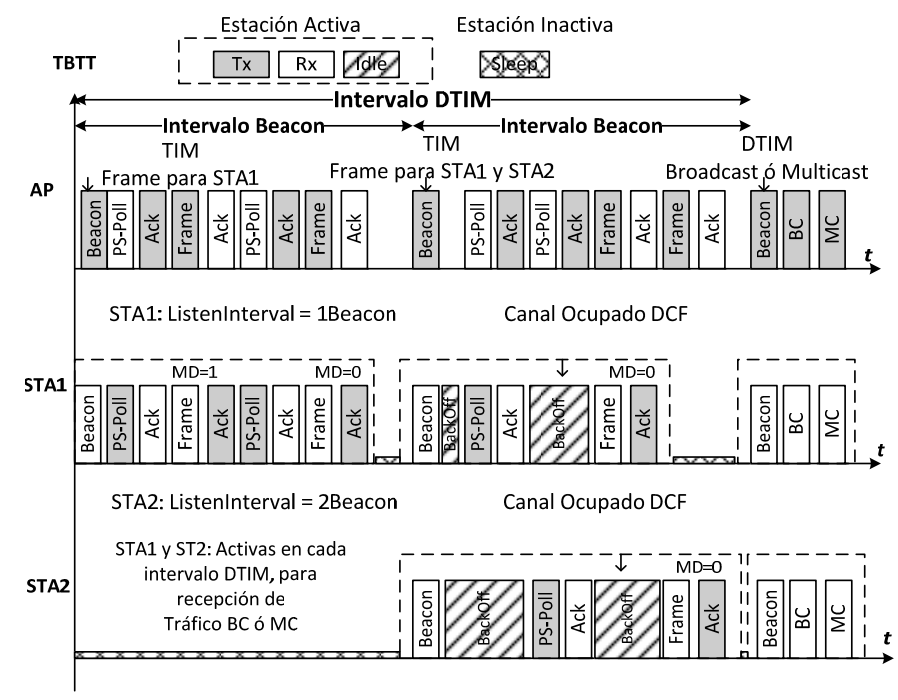

Figura 2. Ejemplo del Sistema de Gestión de Energía PSM-IEEE802.11 en un entorno BSS.

\section{Gestión de Energía: IEEE 802.11e}

APSD es la extensión propuesta en el estándar 802.11e del esquema $P S M$, para un entorno estructurado. $A P S D$ trabaja en conjunto con los mecanismos de QoS de 802.11e, EDCA y HCCA y define a su vez dos variantes: un esquema de gestión de energía distribuido $U$-APSD y uno centralizado $S$-APSD.

El periodo de tiempo durante el cual una estación permanece despierta recibiendo frames enviados por el $A P$ es definido en APSD como el Service Period (SP).

Un $S P$ es iniciado por una estación o un $A P$, dependiendo del mecanismo $A P S D$ y siempre finaliza con la recepción en la estación de un frame con el flag EOSP (End Of Service Period) activado. En $U-A P S D$, las estaciones toman la iniciativa, mediante el envío al $A P$ de notificaciones (triggers) de los instantes cuando se encuentran en modo activo. Cuando la indicación es recibida por el $A P$, éste aprovecha para enviar los frames almacenados durante el intervalo en que la estación se encontraba inactiva. Por el contrario la idea base de 
$S$-APSD es la planificación por el AP de los instantes cuando cada estación debería despertar y activarse para recibir los frames almacenados en el $A P$.

La configuración del tipo de acceso EDCA ó HCCA se realiza mediante la transmisión de un requerimiento $A D D T S$ al $A P$ con los subcampos APSD y Schedule activados. Por otra parte adicionalmente al esquema de prioridades de tráfico definido en el estándar 802.11e, los mecanismos de gestión de energía $U-A P S D$ y $S$-APSD, contribuyen a disminuir la carga de señalización requerida para el intercambio de información.

Específicamente un análisis presentado en [20], establece que la combinación de EDCA y $S-A P S D$, resulta más adecuada para aplicaciones bidireccionales con periodos sin actividad como por ejemplo VoIP, incluso sobre el mecanismo HCCA.

\section{Power Save Mode en una Red modo IBSS (Ad-Hoc)}

La gestión de energía en una red Ad-Hoc no es tan eficiente como en modo BSS, debido a la ausencia de un coordinador central. Sin embargo, al igual que en modo estructurado, la gestión de energía se basa en un tráfico de mensajes informativos que en este caso, deben ser generados de forma distribuida. En modo Ad-Hoc es responsabilidad del nodo transmisor asegurar que el receptor esté activo. A su vez los nodos receptores, con el objetivo de garantizar conectividad deben permanecer más tiempo disponible y no pueden conmutar a modo sleep por los mismos períodos de tiempo como en una red estructurada.

Los mensajes empleados para prevenir a otras estaciones de no ir a modo sleep, se denominan ATIM (Announcement Traffic Indication Message ó Ad-Hoc Traffic Indication Message). Debido a la ausencia de un coordinador central, durante cada intervalo Beacon todas las estaciones deben permanecer activas durante un tiempo denominado ventana ATIM (ATIM_W), con el objetivo de anunciar o verificar la existencia de tráfico. En caso de recibir o transmitir un mensaje ATIM, la estación deberá permanecer activa por el resto del intervalo Beacon o hasta finalizar la transmisión o recepción de datos. Se resalta además que el mecanismo de gestión definido en el estándar para modo IBSS, se refiere a un entorno uni-salto. En relación al estado de operación de los nodos, en la Tabla I se presentan los casos posibles y adicionalmente en la figura 3 se presenta el esquema de gestión descrito.

TABLA I: CASOS Y ESTADOS PERMITIDOS PARA UN NODO IBSS.

\begin{tabular}{|l|l|}
\hline Caso & \multicolumn{1}{|c|}{ Nodo Ad-hoc } \\
\hline Nodo Transmite un ATIM & Activa Intervalo Beacon \\
\hline Recibe un ATIM & Activa Intervalo Beacon \\
\hline Transmite y Recibe un ATIM & Activa Intervalo Beacon \\
\hline No Transmite ni Recibe ATIM's & Sleep \\
\hline
\end{tabular}

\section{PROPUESTA: ESQUEMA DE BUFFERING APLICADO A IBSS}

Como se mencionó anteriormente, debido a la ausencia de un coordinador central, la gestión de energía en un entorno Ad-Hoc se realiza de forma distribuida. A continuación se presentan algunas observaciones al mecanismo definido en el estándar y posteriormente el planteamiento de una propuesta.

\section{A. Intervalos de Actividad de las Estaciones Ad-Hoc}

A diferencia de un entorno estructurado, donde las estaciones pueden acordar con el AP los intervalos de actividad, permaneciendo en modo de ahorro de energía (sleep) durante un número $n$ de transmisiones Beacon, el mecanismo de gestión de energía para modo IBSS, requiere que las estaciones, conmuten a modo activo, durante un tiempo (ATIM_W) en cada ocurrencia Beacon (TTBT). Por tanto se genera un gasto de energía fijo en cada intervalo.

Adicionalmente y posterior a la ventana ATIM, la posibilidad de la estación de cambiar al estado de ahorro de energía, se reduce a la condición de no haber transmitido ó recibido ningún frame ATIM.

El condicionamiento mencionado contribuye a generar mayores periodos de actividad y un mayor consumo de energía. Un ejemplo del comportamiento analizado se presenta en el esquema de la Fig. 3. Mientras la estación 1, luego de la ocurrencia del primer intervalo Beacon, no recibe ni transmite frames ATIM, únicamente tiene periodos fijos de actividad correspondiente a la ventana. Por el contrario, la estación 2 al recibir mensajes ATIM durante dos intervalos consecutivos, permanece activa durante un mayor tiempo.

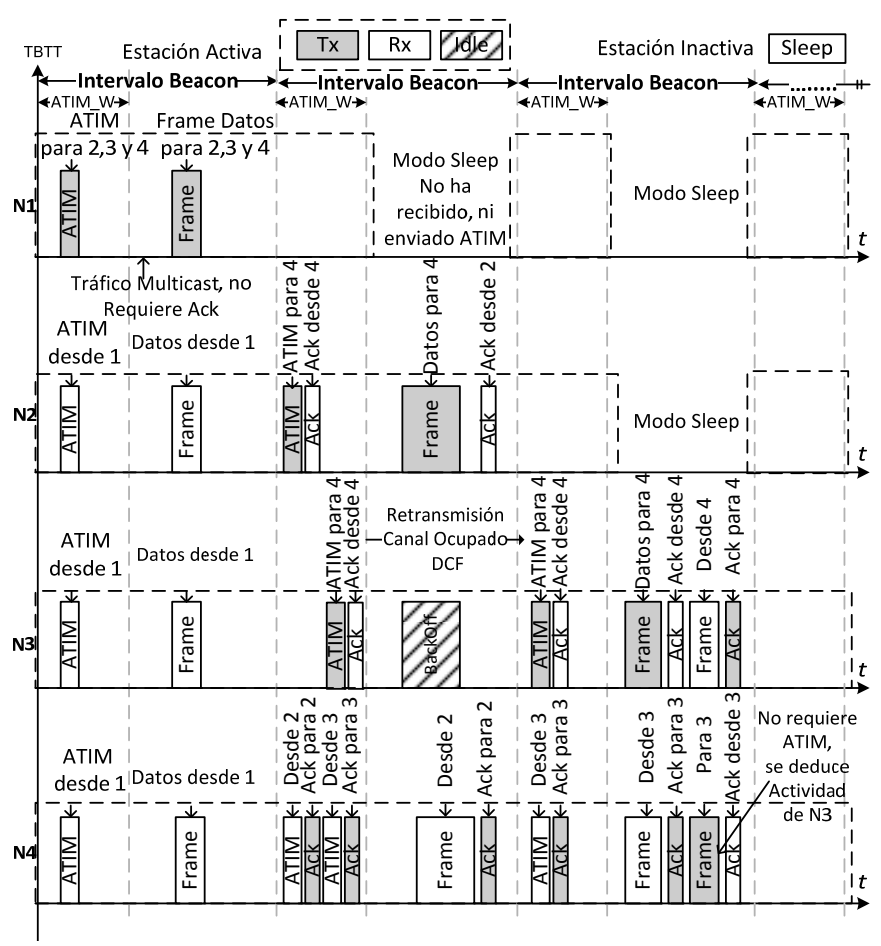

Figura 3. Ejemplo del Sistema de Gestión de Energía PSM-IEEE802.11 en un Entorno IBSS, [21]. 
Para evitar los periodos excesivos de actividad, al igual que en modo BSS, una estación Ad-Hoc puede verificar el bit $M D$ (ó EOSP, en caso de tráfico diferenciado EDCA), para comprobar si existe más datos a recibir y conmutar a modo sleep antes de finalizar un intervalo Beacon. Sin embargo en función de la cantidad de frames ATIM, que la estación escuche o transmita durante la ventana, el estándar describe la posibilidad de periodos continuos de actividad hasta la siguiente ventana.

Adicionalmente si una estación no logró transmitir frames previamente anunciados, debido a la contención por el canal, debe retransmitir el mensaje ATIM en la siguiente ventana, para alertar a otra estación o al resto de estaciones de permanecer activas.

Todo esto contribuye a reducir significativamente el tiempo durante el cual una estación puede permanecer en modo de ahorro de energía, como se puede apreciar en el comportamiento de las estaciones 3 y 4 .

\section{B. Técnica de Buffering: Antecedentes}

Un esquema de gestión de energía basado en buffering, consiste en almacenar una cierta cantidad de información direccionada a una estación durante un periodo, permitiéndole permanecer inactiva, para su posterior transmisión cuando se encuentre en modo activo. Este mecanismo se emplea actualmente en el esquema de gestión de energía del estándar IEEE 802.11, para modo estructurado (BSS). Un mecanismo similar se aplica en el estándar DVB-H (Digital Video Broadcasting Handheld), enfocado a la difusión de TV para dispositivos portátiles.

$D V B-H$, emplea un esquema denominado time-slicing [22], para la gestión de energía, consistente en el envío de datos en ráfagas usando un bit rate instantáneo significativamente mayor, comparado con el requerido si los datos fueran transmitidos usando mecanismos de streaming tradicionales.

En la ráfaga se incluye información acerca de los instantes de ocurrencia de las próximas transmisiones, permitiendo a las estaciones permanecer activas únicamente por una fracción de tiempo.

Los dos esquemas de gestión de energía emplean un coordinador central dentro de su estructura de red. El coordinador o estación central tiene acceso directo a una fuente de energía y ejecuta un trabajo intenso de almacenamiento y transmisión de información.

\section{Esquema de Buffering Propuesto}

Conforme al análisis realizado, los mensajes ATIM contribuyen a generar extensos periodos de actividad en las estaciones debido a su frecuencia de generación.

En ese sentido se propone modificar éste tipo de señalización por un mensaje de notificación de buffer que permita a las estaciones Ad-Hoc, permanecer en modo sleep durante varios intervalos Beacon.

En esta propuesta se ha denominado a éste tipo de mensaje ATIB (Announcement Traffic Indication Buffer). El objetivo del mensaje es similar a la funcionalidad del frame ATIM.

Es decir, alertar a una estación de mantenerse activa, pero en éste caso debido a la existencia de un conjunto de datos pendientes a transmitir (buffer). Una vez almacenados, durante los periodos de envío los datos pueden ser depositados en el canal a una tasa mayor de envío, debido a que han sido generados previamente por la aplicación, de una forma similar al concepto time slicing empleado en $\mathrm{DVB}-\mathrm{H}$.

La extensión de los periodos de inactividad de las estaciones en consecuencia depende de la frecuencia de generación de mensajes ATIB y por tanto del tamaño de buffer. A su vez, asociado a un tamaño de buffer existe un tiempo de almacenamiento durante el cual una estación acumulará los datos a enviar posteriormente.

Este concepto es similar a los periodos listen interval, definidos en modo BSS y que son acordados con el AP.

En la Fig. 4, se presenta un diagrama comparativo de los mensajes de notificación ATIM y el esquema ATIB propuesto.

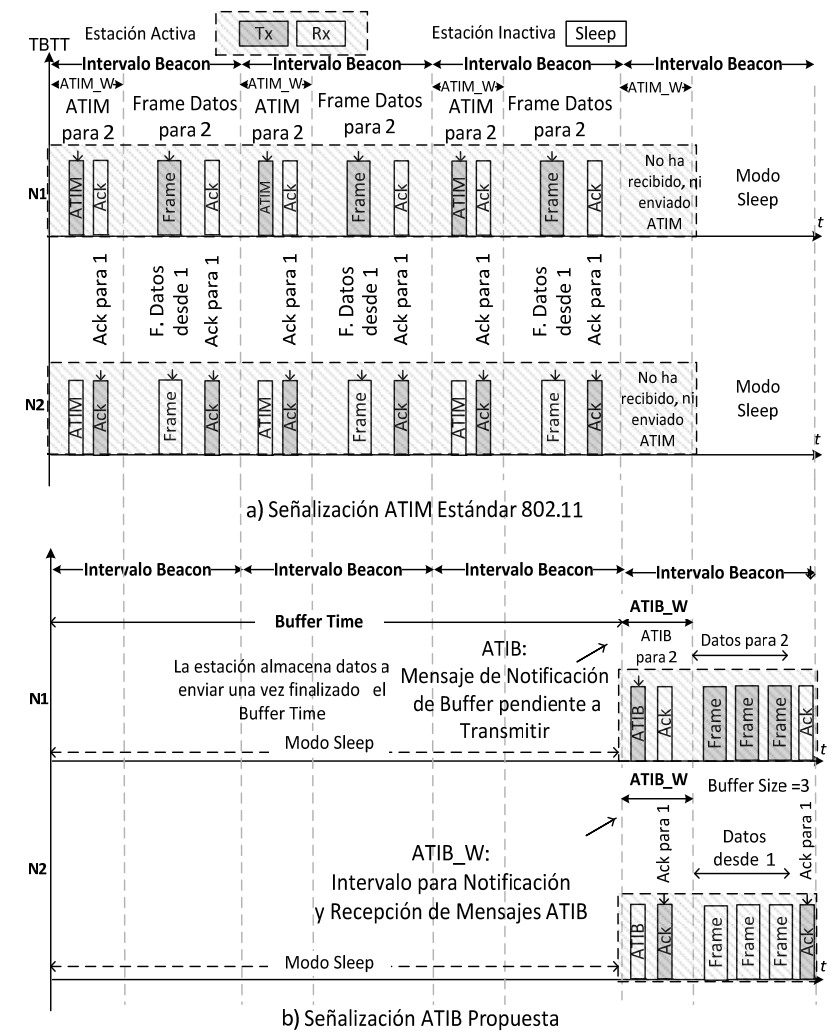

Figura 4. Comparación de Operación de Esquemas IEEE 802.11 y Buffering. a) Señalización ATIM, las estaciones se activan en cada intervalo Beacon, para transmisión - recepción de datos. b) Esquema propuesto, la estación 1 almacena datos durante un periodo Buffer Time y envía el buffer almacenado previo anuncio mediante un mensaje de notificación de buffer ATIB. Las estaciones se mantienen en modo de ahorro de energía durante el Buffer Time.

\section{EVALUACIÓN DE LA PROPUESTA}

Para evaluar el esquema de buffering propuesto se empleó el simulador NS3. Específicamente se realizó un análisis del consumo de energía, empleando diferentes tamaños de buffer.

El modulo de energía disponible en el simulador emplea la Ecuación (1) para dimensionar el consumo en un intervalo $\left(t_{i}, t_{i}+1\right)$. 
En [23] se presenta una descripción detallada del framework de energía disponible en NS3.

$$
E_{i+1}=E_{i}+V \bullet\left(t_{i+1}-t_{i}\right) \bullet I_{i}
$$

Donde $V$ es la tensión e $I_{i}$, es el nivel de intensidad instantáneo de acuerdo al estado de la interfaz de radio $(T x$, $R x$, idle ó sleep). Para la evaluación, los valores de consumo de energía empleados corresponden a la tarjeta Intel Pro/Wireless 3945ABG.

Ahora bien, a pesar de la posibilidad de configurar el valor de intensidad para modo sleep, en realidad éste valor no se emplea, debido a que actualmente NS3 no soporta el mecanismo de gestión de energía (PSM) definido en el estándar, con lo cual el estado de menor consumo de energía, corresponde al modo idle. Para desarrollar las simulaciones en consecuencia se trabajará a nivel de la capa de aplicación, como alternativa para gestionar el almacenamiento de datos y los instantes de envío.

Mediante dicha estrategia es posible reproducir un comportamiento muy similar al generado por la señalización de los mensajes ATIM, en términos de transmisión de datos e intervalos de ahorro de energía. La diferencia más significativa se presenta en el nivel de consumo de energía durante el periodo de ahorro, que en éste caso corresponde a modo idle y no sleep, como plantea el estándar.

\section{A. Parámetros de Simulación}

Para generar los diferentes tamaños de buffer y configurar los instantes de transmisión se emplea la funcionalidad de tráfico On/Off, disponible en NS3. El escenario para evaluar la propuesta está conformada por dos nodos en modo Ad-Hoc.

Considerando los parámetros de consumo presentados en la Fig. 1, un estado de transmisión continuo durante un minuto, requiere alrededor de $100 \mathrm{~J}$ de energía. Con tal referencia se fijo un valor de 150J como energía inicial para los nodos, para un tiempo de simulación de 60 segundos.

El tamaño de los paquetes y la tasa de generación han sido configurados para emular una aplicación de VoIP, los parámetros empleados se presentan en la Tabla II. Los valores han sido obtenidos en capturas realizadas previamente empleando un analizador de protocolos, durante la ejecución de una conversación mediante la aplicación Skype.

TABLA II: PARÁMETROS DE TAMAÑO DE BUFFER Y TIEMPO DE ALMACENAMIENTO EMPLEADOS EN LA SIMULACIÓN.

\begin{tabular}{|c|c|c|}
\hline Buffer Size & Buffer Time & Correspondiente a \\
\hline 1 & $8 \mathrm{~ms}$ & 1 paquete \\
\hline 10 & $80 \mathrm{~ms}$ & 10 paquetes \\
\hline 100 & $800 \mathrm{~ms}$ & 100 paquetes \\
\hline 200 & $1.6 \mathrm{~s}$ & 200 paquetes \\
\hline 500 & $4 \mathrm{~s}$ & 500 paquetes \\
\hline
\end{tabular}

\section{B. Resultados Obtenidos}

En la Fig. 5, se presentan los resultados correspondientes a la energía residual empleando diferentes tamaños de buffer.

Se asignó por defecto un tiempo de 30 segundos para la convergencia del protocolo OLSR, mientra que el inicio de la transmisión se fijó a los 31 segundos, con lo cual durante éste primer intervalo el consumo de energía es el mismo en todos los casos y corresponde a información de enrutamiento.

A continuación el proceso de transmisión está definido por dos intervalos: almacenamiento y envío de paquetes.

Dichos intervalos están caracterizados por un valor de pendiente $(\Delta \mathrm{E} / \Delta \mathrm{t})$, la cual es mayor durante los instantes de transmisión de las ráfagas.

La duración de las pendientes a través del tiempo genera una diferencia en el consumo de energía, obteniéndose mayores valores de energía residual conforme se incrementa el tamaño del buffer, como se puede apreciar en la Fig. 5 al término de 60 segundos de simulación.

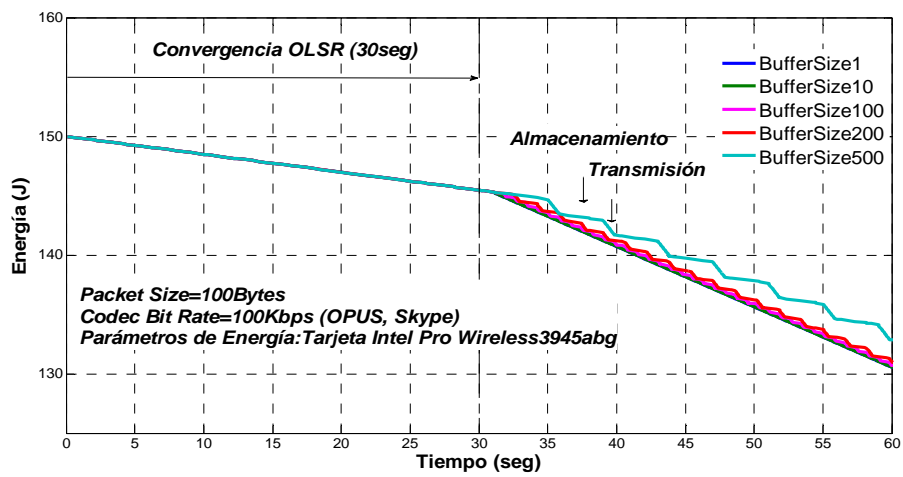

Figura 5. Medición de Energía Residual en Nodo Transmisor, empleando diferentes tamaños de buffer.

Una ampliación por secciones de ésta gráfica, se presenta en la Fig. 6, con el objetivo de visualizar con detalle los intervalos mencionados para los diferentes tamaños de buffer.

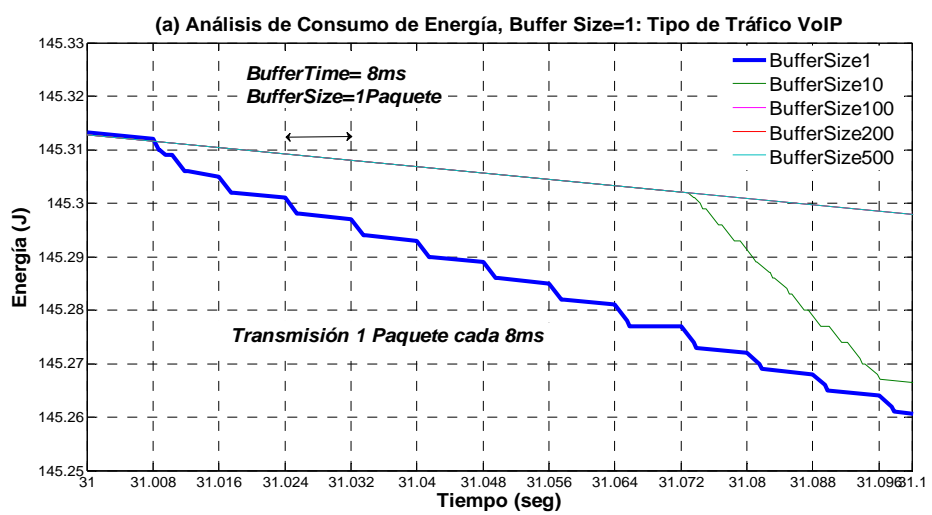


(b) Análisis de Consumo de Energía, Buffer Size $=10$ : Tipo de Tráfico VolP
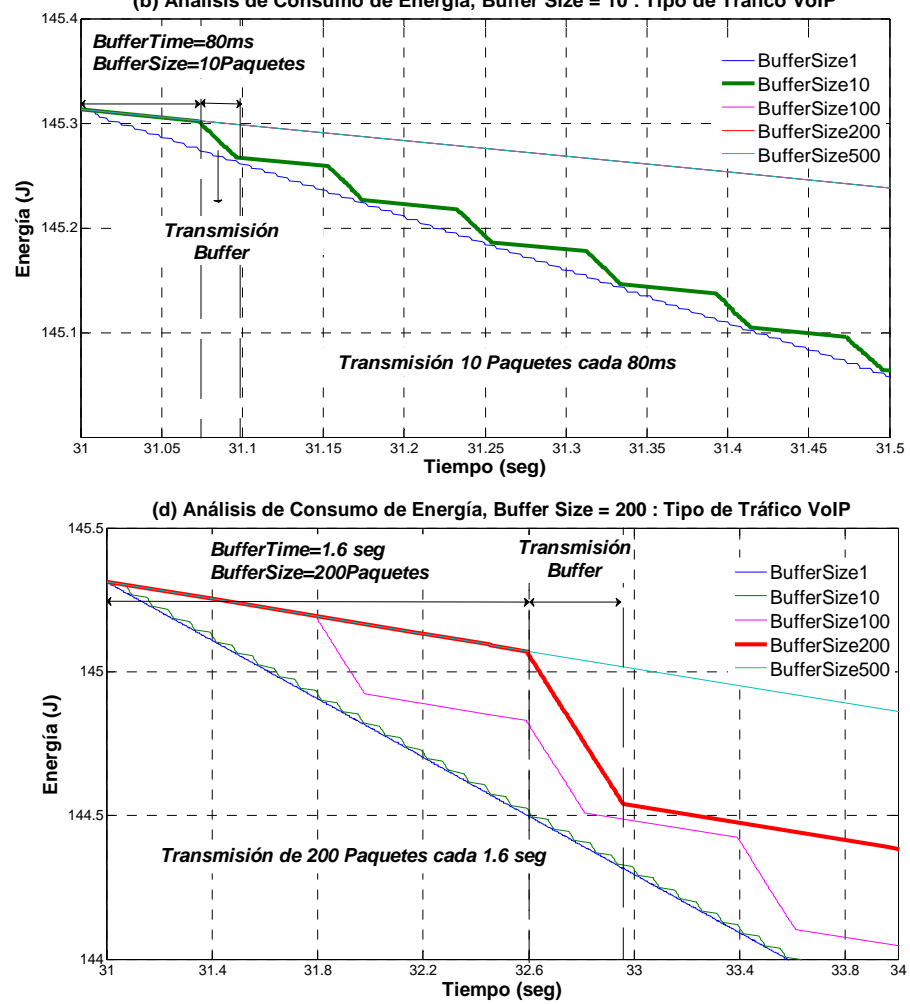

(c) Análisis de Consumo de Energía, Buffer Size = 100 : Tipo de Tráfico VolP

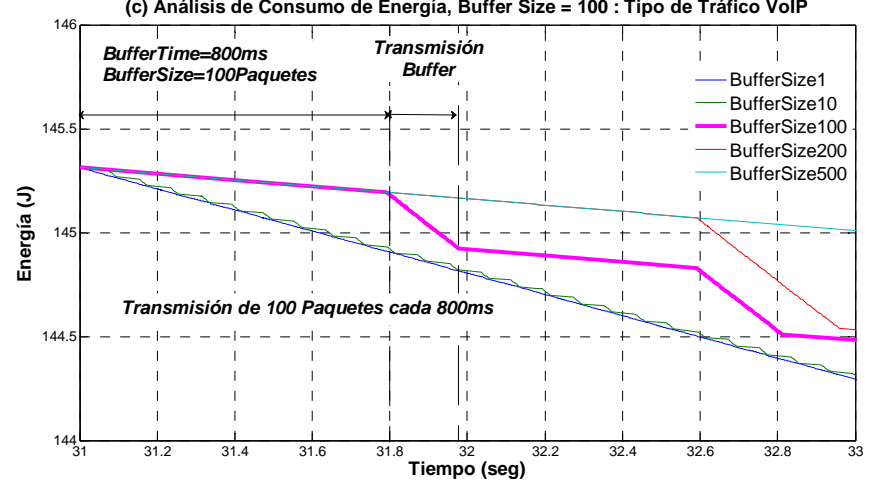

Figura 6. Intervalos de Almacenamiento y Transmisión de Paquetes (a) Buffer Size=1. (b) Buffer Size = 10. (c) Buffer Size = 100. (d) Buffer Size =200.

Durante el intervalo de almacenamiento el consumo de energía caracterizado por una pendiente menor, corresponde a la permanencia en estado idle del nodo y al intercambio de información de enrutamiento.

Por otra parte mayores tiempos de simulación han permitido verificar un incremento continuo de ahorro de energía.

En la Fig. 7, se presenta este comportamiento, mediante una comparación entre el máximo tamaño de buffer y el mínimo empleado.

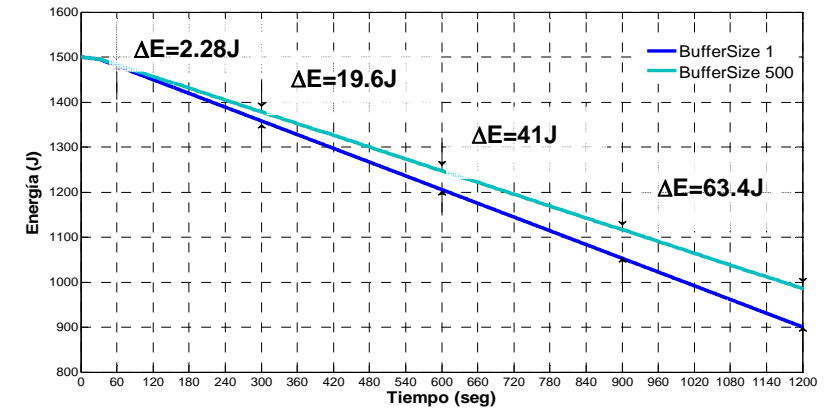

Figura 7. Comparación en el Tiempo de los Valores de Energía Residual entre el Máximo y el Mínimo Tamaño de Buffer Empleado.

En general el ahorro de energía en el esquema propuesto se obtiene al extender los periodos de menor consumo de energía de las estaciones. Dicho comportamiento se ve reflejado en los estados de operación de la interfaz de radio. En la Fig. 8, se presenta diagramas comparativos obtenidos de la simulación respecto a la actividad de la interfaz radio para tamaños de buffer de 1 y 500 paquetes.
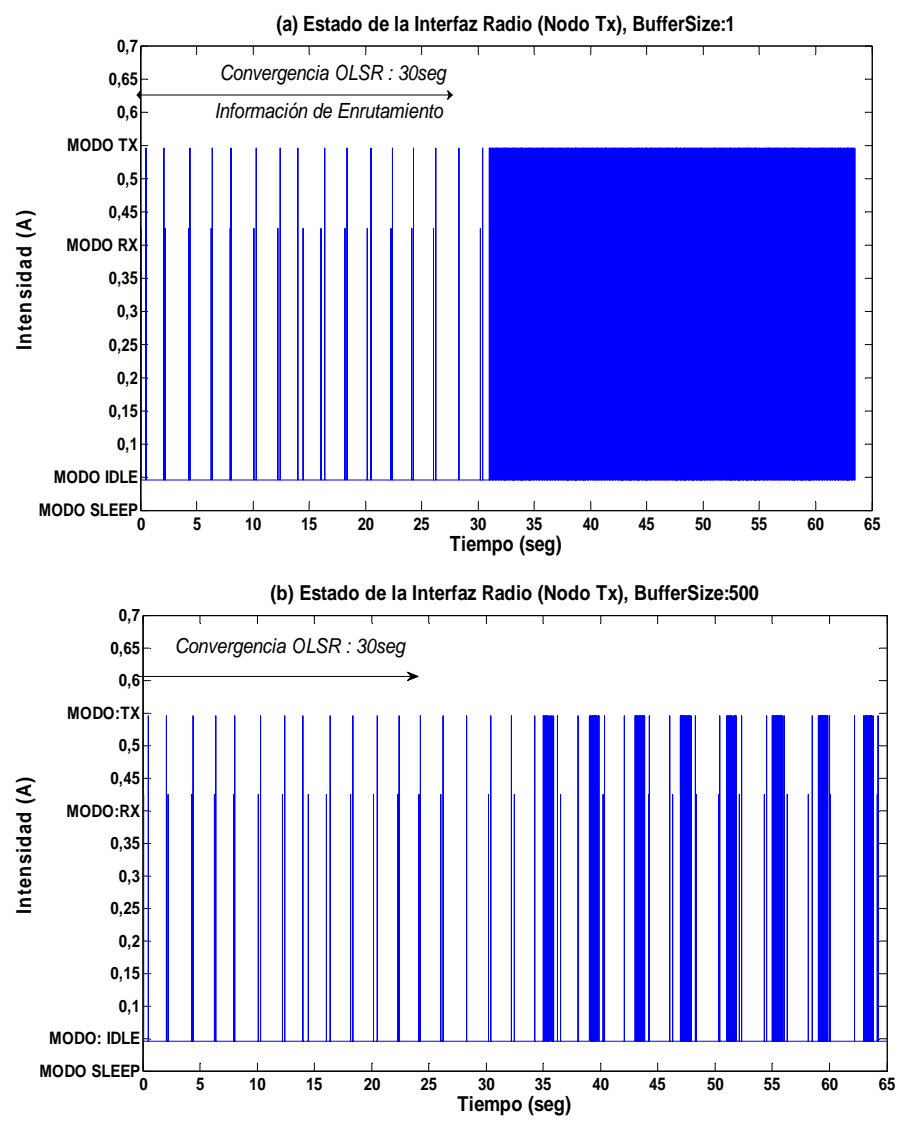

Figura 8. Estados de Operación de la Interfaz Radio para Distintos Tamaños de Buffer. (a) Buffer Size =1. (b) Buffer Size $=500$.

Como se puede apreciar para un tamaño de buffer igual a 1 , la interfaz radio permanece en constante actividad y no es posible visualizar periodos de menor consumo de energía. Por el contrario para el máximo tamaño de buffer empleado es posible apreciar periodos de menor actividad de la interfaz 
(estado idle), mientras que la transmisión de los paquetes almacenados se concentra en ráfagas.

Se prevé obtener mayores niveles de ahorro con una operación en modo sleep, no disponible actualmente en el simulador, como se mencionó anteriormente.

Adicionalmente, con el objetivo de comprobar los resultados obtenidos en las simulaciones, se realizó pruebas con equipos reales, para lo cual se configuró una red Ad-Hoc, conformada por dos ordenadores, y mediante un script linux se realizó la transmisión de paquetes de acuerdo a los parámetros de la Tabla II, y se capturó el consumo de energía en cada envío.

Los resultados obtenidos se presentan en la Fig. 9. Como se puede apreciar, las mediciones siguen la tendencia de la simulación. Es decir conforme se incrementa el tamaño de paquetes almacenados para su posterior envío, el consumo de energía es menor.

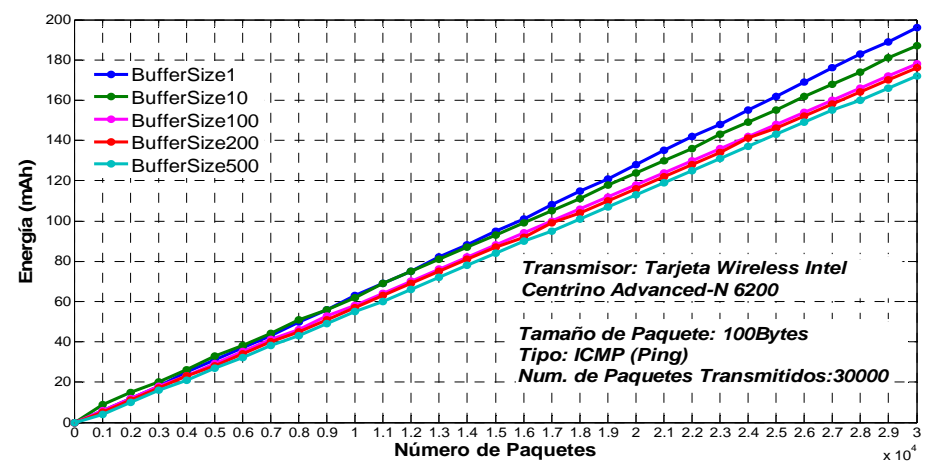

Figura 9. Mediciones de Consumo de Energía Realizada en Equipos, con Diferentes Tamaños de Buffer.

\section{CONCLUSIONES}

Actualmente existe un conjunto de propuestas que abordan el problema del balance entre calidad de servicio y consumo de energía, en un entorno Ad-Hoc, dichos trabajos plantean estrategias de gestión a partir de una capa específica de red.

En ese sentido un enfoque que aproveche en conjunto las capacidades de gestión de cada capa resulta más eficiente, éste tipo de diseño se denomina cross-layer.

Por otra parte, un análisis de los mecanismos de gestión estandarizados resulta adecuado. En ese sentido se ha determinado que el estándar IEEE 802.11, plantea conceptos generales para la gestión de energía en un entorno Ad-Hoc.

Dicho esquema presenta algunos inconvenientes como por ejemplo la generación de extensos periodos de actividad de las estaciones y periodos fijos de consumo de energía en cada intervalo Beacon. Adicionalmente la integración con mecanismos de gestión de energía mejorados como APSD en un entorno IBSS, no ha sido detallado en el estándar, en consecuencia el esquema actual genera la posibilidad para el planteamiento de extensiones.

Específicamente una estrategia de almacenamiento mejora significativamente el desempeño del mecanismo en términos de gestión de energía. En ese sentido, los resultados obtenidos en el presente artículo tanto en simulaciones como en las mediciones realizadas con equipos reales indican que el esquema de buffering planteado permite optimizar el consumo de energía a través del incremento de los periodos en los cuales las estaciones permanecen en un estado de menor consumo de energía. Dicho ahorro de energía aumenta, conforme se incrementa el tamaño de buffer empleado.

Finalmente aunque esquemas similares se implementan actualmente en entornos estructurados (BSS) y en otro tipo de escenarios como por ejemplo difusión de TV. Digital en dispositivos portátiles $(D V B-H)$. Sin embargo su aplicación no es directa en un entorno Ad-Hoc, debido a la ausencia de un coordinador central, en consecuencia es necesario trabajar con mecanismos de gestión distribuidos, para un entorno IBSS.

\section{TRABAJO FUTURO}

A partir de la investigación realizada, se plantea las siguientes líneas como trabajo futuro: Desarrollo de un Framework de Gestión de Energía en NS3, basado en el estándar IEEE.802.11. Esta herramienta permitirá experimentación a nivel MAC, específicamente en relación a señalización e implementación de extensiones y propuestas de esquemas de gestión de energía como el planteado en el presente artículo. En principio, se requiere trabajar sobre el soporte de frames Beacon para escenarios Ad-Hoc, y frames de control para notificación de tráfico pendiente a transmitir.

Otro trabajo futuro se enfoca en el diseño e implementación de un esquema cross-layer, para el balance entre calidad de servicio y eficiencia en el consumo de energía en redes AdHoc. El esquema requiere un análisis de los aportes que cada capa puede generar a nivel de gestión y la definición del tipo de información a intercambiar entre ellas.

\section{AGRADECIMIENTOS}

El presente trabajo se realizó con el apoyo de la Secretaría Nacional de Educación Superior, Ciencia Tecnología e Innovación del Gobierno de Ecuador (beca 195-2012).

\section{REFERENCIAS}

[1] M.Conti, S.Giordano, "Mobile Ad-Hoc Networking: Milestones, Challenges and New Research Directions" IEEE Communications Magazine, vol. 52, no.1, pp. 85-96, January. 2014.

[2] IEEE Estandars Association, "Part 11: Wireless LAN Medium Access Control (MAC) and Physical Layer (PHY) Specifications", IEEE Computer Society, IEEE-SA Standard Board, Section 10.2 Power Management, pp. 984-1009, Approved 6 February 2012.

[3] Yang Liu, Itamar Elhanany, Hairong Qi, "An Energy-Efficient QoSAware Media Access Control Protocol for Wireless Sensor Networks", IEEE MASS 2005.

[4] Byung Joon Oh, Chang Wen Chen, "Energy Efficient H.264 Video Transmission over Wireless Ad-Hoc Networks Based on Adaptive 802.11e EDCA MAC Protocol”, ICME 2008.

[5] Alam M, Aveiro, Albano M, "Context Based Node Discovery Mechanism for Energy Efficiency in Wireless Networks“, IEEE International Conference, pp. 6008 - 6012, 2012.

[6] Memarzadeh H., Dehghan, M, Jabbehdari S, "A New Quorum-Based Power Saving Protocol to Maintain QoS for MANETs with Burst Traffics", Advanced Information Networking and Applications, Workshops (WAINA), IEEE 24th International Conference, pp. $674-$ 679, 2010.

[7] Yuvaraju B.N, Mohit, T, Chiplunkar, "Enhancing the Performance of MANETs by Monitoring the Energy Consumption and Use of Mobile 
Relays”, Computer Science and Information Technology - Spring Conference, IACSITSC 2009.

[8] Haiyang Zhang, "Cluster-to-Cluster Overlay Network for Video Systems over Wireless Ad Hoc Networks" Mobile Ad-hoc and Sensor Networks (MSN), Seventh International Conference, pp. 356 - 357, 2011.

[9] Jalel Ben-Othman, Bashir Yahya, "Energy Efficient and QoS Based Routing Protocol for Wireless Sensor Networks", J. Parallel Distrib. Comput, Department of Computer Science, PRiSM Laboratory, University of Versailles Saint Quenti, March 2010.

[10] Dionisis Kandris, Michail Tsagkaropoulos, "Energy Efficient and Perceived QoS Aware Video Routing over Wireless Multimedia Sensor Networks", ELSEVIER Ad Hoc Networks, 2010.

[11] E.D.Kanmani Ruby, N.Kasthuri, "QoS Enhancement using Efficient Routing Protocol for Video over Wireless Adhoc Networks", International Conference on Advanced Computer Technology (ICACT) Proceedings published by International Journal of Computer Applications(IJCA), 2011.

[12] Linfeng Yuan, Wenqing Cheng, "An Energy-Efficient Real-Time Routing Protocol for Sensor Networks", ELSEVIER, Computer Communications, 2007.

[13] Navrati Saxena, Abhishek Roy, "QuESt: a QoS-Based Energy Efficient Sensor Routing Protocol”, Wireless Communications and Mobile Computing, John Wiley \& Sons, 2009.

[14] Ajina A, G.R.Sakthidharan, "Study of Energy Efficient, Power Aware Routing Algorithm and Their Applications, Second International Conference on Machine Learning and Computing”, IEEE Computer Society, 2010

[15] Lamia Kaddar, Yassine Hadjadj-Aoul, "EVAN: Energy-aware SVC Video Streaming over Wireless Ad hoc Networks”, 2011 IEEE.

[16] Zheng Wu, Jiankang Wu, "Cross-layer Routing Optimization for Video Transmission over Wireless Ad Hoc Networks", Wireless Communications Networking and Mobile Computing (WiCOM), 2010.

[17] Wen-Ping Lai, En-Cheng Liou, “A novel cross-layer design using combshaped quadratic packet mapping for video delivery over 802.11e wireless Ad-Hoc Networks", EURASIP Journal of Wireless Communications and Networking, 2012.

[18] ElAttar. H, Abdelaty. H, "PHY-MAC Cross-Layer Optimized Design for Power Conservation in Wireless Ad Hoc Networks", New Technologies, Mobility and Security (NTMS), 2011.

[19] Jing Zuo, Chen Dong, Hung Viet Nguyen, "Cross-Layer Aided EnergyEfficient Opportunistic Routing in Ad Hoc Networks", Communications, IEEE Transactions, Volume 62, 2014.

[20] Pérez Xavier, Camps Daniel, "IEEE 802.11e QoS and Power Saving Features Overview and Analysis of Combined Performance”, IEEE Wireless Communications, NEC Laboratories Europe, 2010.

[21] Matthew S. Gast, "802.11 Wireless Networks The Definitive Guide", O’Reilly, 2da Edición, 2005, pp. 188-199.

[22] European Standard (Telecommunications Series), "Digital Video Broadcasting (DVB)", Transmissions System for Handheld Terminals (DVB-H), European Telecommunications Standards Institute 2004.

[23] He Wu, Radha Poovendran, "An Energy Framework for the Network Simulator 3 (ns-3)", University of Washington, Seattle, USA, Copyright 2011 ICST.

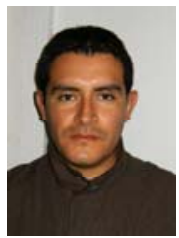

Santiago González, received the Electronic Engineering degree from the Universidad Politécnica Salesiana (UPS), Cuenca- Ecuador, in 2006 and M.S Degree in Tecnologías Informáticas Avanzadas, from Universidad Castilla-La Mancha, Ciudad Real, Spain, 2009. From 2010 to 2013 he worked as professor at Electronic and Telecommunications Engineering School-Universidad de Cuenca (Ecuador). Currently, he is a Researcher at the Multimedia Communications research group (COMM) of the Institute of Telecommunications and Multimedia Applications (iTEAM), UPV, where he is working toward the Ph.D. degree. His research interests include Energy Efficiency and QoS on Wireless Ad-Hoc Networks.

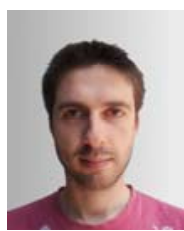

Pau Arce, received his Telecommunications Engineering degree, M.S. in Telematics and the Ph.D degree in Telecommunications from the Universitat Politècnica de València (UPV), Spain, in 2005, 2007 and 2014 respectively. Currently he works as a researcher at the Institute of Telecommunications and Multimedia Applications (iTEAM). His research interests include multimedia QoS, routing on wireless ad hoc networks and performance evaluation of computer systems.

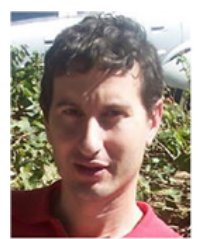

Juan Carlos Guerri, received the M.S. and Ph.D. (Dr.Ing.) degrees, both in Telecommunication engineering, from the Universitat Politècnica de València (UPV), Valencia, Spain, in 1993 and 1997, respectively. $\mathrm{He}$ is a Professor in E.T.S. Telecommunications Engineering at the UPV, where he leads the Multimedia Communications research group (COMM) of the iTEAM Institute. $\mathrm{He}$ is currently involved in research and development projects for the application of multimedia to industry, medicine, education, and communications. 